\title{
Optimization of conditions for transfection with the Sofast gene vector
}

\author{
LEI ZHOU ${ }^{1}$, FAN LIU ${ }^{2}$, FANG-FANG QIAO ${ }^{3}$, MAN-LI TONG ${ }^{2,4}$, ZUO-GEN FU $^{2,4}$, \\ BING DAN $^{2,4}$, TIAN-CI YANG ${ }^{4}$ and ZHONG-YING ZHANG ${ }^{4}$
}

\author{
${ }^{1}$ Department of Cardiology, The First Affiliated Hospital of Nanjing Medical University, Nanjing 210029; \\ ${ }^{2}$ Medical College of Xiamen University, Xiamen 361005; ${ }^{3}$ School of Life Sciences, Xiamen University, Xiamen 361005; \\ ${ }^{4}$ Center of Clinical Laboratory, Zhongshan Hospital, Medical College of Xiamen University, Xiamen 361004, P.R. China
}

Received September 3, 2010; Accepted November 25, 2010

DOI: $10.3892 / \mathrm{mmr} .2010 .404$

\begin{abstract}
We previously reported the synthesis and characterization of a novel cationic polymer gene vector. The present article further explored and optimized the working conditions of the Sofast gene vector both in vitro and in vivo, and improved its performance. The transfection conditions of Sofast, such as cell type, cell density, transfection time, N/P values and analysis time after transfection, were further explored. Moreover, the effects of the fusion peptide diINF-7 on transfection efficiency were examined. Sofast was successfully applied for the transfection of exogenous genes into more than 40 types of cell lines derived from humans, mice, monkeys and other species. When the cells were 50-80\% confluent, Sofast possessed a better transfection efficiency. In most cases, Sofast also had a higher transfection efficiency when it was used to transfect cells that were seeded for several hours and had adhered to the substrate. The results from in vitro experiments indicate that the recommended Sofast to DNA mass ratio is $16: 1$, and the optimum analysis time after transfection is $48 \mathrm{~h}$. The salt concentration in the Sofast working solution markedly affected the transfection efficiency. When conducting in vivo transfection, the working solution should be salt-free, whereas for in vitro transfection, it is more appropriate for the working solution to include certain salt concentrations. Finally, the results confirm that diINF-7 significantly promotes the transfection efficiency of Sofast. In conclusion, the present research not only established the optimal conditions for Sofast in the transfection of commonly used cells, but also built the foundations for
\end{abstract}

Correspondence to: Dr Tian-Ci Yang and Professor Zhong-Ying Zhang, Center of Clinical Laboratory, Zhongshan Hospital, Medical College of Xiamen University, Xiamen 361004, P.R. China

E-mail: yangtianci@xmu.edu.cn; zhangzy1121@xmu.edu.cn

Key words: cationic polymer, gene vector, transfection, optimization in vivo and in vitro applications of Sofast, as well as its use in clinical practice.

\section{Introduction}

Due to the complicated manipulations and potential safety hazards of viral vectors, non-viral gene vectors are currently used to facilitate the delivery of target genes and to penetrate the cellular membrane barrier (1). Cationic polymers recruit DNA through electrostatic adsorption and form a nano-scale polyelectrolyte complex (PEC), which enters the cells by endocytosis and protects genes from nuclease I (2). Watersoluble cationic polymers form stable PECs by condensing DNA, penetrate the cell membrane by simulating the structure of the virus, and are finally degraded in the cell (3). They confer no risk of carcinogenesis, whereas a virus does, and show broad application prospects, which has led them to become the focus of the focus of intense study in the research and development of non-viral gene vectors (4). Although cationic polymers possess many advantages compared to viral gene vectors, several problems remain to be solved, such as their low transfection efficiency, weak degradability and poor biocompatibility, all of which limit their development (5).

Our group has synthesized a cationic polymer with branch structures, and has constructed a Sofast gene vector which has been used to transfer macromolecular nucleic acids both in vivo and in vitro (2). In our previous study, we thoroughly investigated the characteristics of Sofast, including its transfection efficiency, cytotoxicity, cell type and compatibility with serum, as well as the stability of its physicochemical properties and its biocompatibility. Through the above tests, we verified that Sofast is a gene vector with a high transfection efficiency, low cytotoxicity and good stability, and that it has the potential to be widely used in gene transfection both in vitro and in vivo.

The present study aimed to optimize the transfection conditions of Sofast, including cell type, cell confluence, transfection time, N/P values and the salt concentrations of working solutions. We also examined the effects of the fusion peptide diINF-7 on transfection efficiency. The results establish the optimal working conditions for Sofast in the transfection of commonly used cells. 
Table I. Recommended initial number of cells seeded in cell culture devices.

\begin{tabular}{lccc}
\hline Cell culture devices & Areas of device $\left(\mathrm{mm}^{2}\right)$ & Cell number & Final volume of medium \\
\hline 96-well plates & 50 & $1.5-5.0 \times 10^{4}$ & $100 \mu 1$ \\
48 -well plates & 100 & $3.0 \times 10^{4}-1.0 \times 10^{5}$ & $200 \mu 1$ \\
24-well plates & 200 & $8.0 \times 10^{4}-2.0 \times 10^{5}$ & $500 \mu 1$ \\
12-well plates & 401 & $1.6-4.0 \times 10^{5}$ & $1.0 \mathrm{ml}$ \\
6-well plates & 962 & $3.0-8.0 \times 10^{5}$ & $2.0 \mathrm{ml}$ \\
35-mm Petri dishes & 962 & $3.0-8.0 \times 10^{5}$ & $2.0 \mathrm{ml}$ \\
60-mm Petri dishes & 2827 & $1.0-2.5 \times 10^{6}$ & $6.0 \mathrm{ml}$ \\
$100-\mathrm{mm}$ Petri dishes & 7854 & $2.5-6.4 \times 10^{6}$ & $10.0 \mathrm{ml}$ \\
\hline
\end{tabular}

\section{Materials and methods}

Dimethyl sulfoxide (DMSO) and glycerol were purchased from Ximen Luyin Co. (China). Opti-minimum essential medium (Opti-MEM), Dulbecco's modified Eagle's medium (DMEM) and Eosin Methylene Blue Agar (EMB) were purchased from Gibco (USA). The plasmids pEGFPN1 and pCMV-lacZ were purchased from Clontech Co. (USA). pGL3 plasmid was from Promega (USA). Lipofectamine 2000 was purchased from Invitrogen (USA). CytoPure and JetPEI were purchased from Qbiogene (USA). SuperFect was purchased from Qiagen (USA). All cell lines were purchased from the American Type Culture Collection (ATCC). The guinea pigs were from the Xiamen University Laboratory Animal Center (XMULAC). All animal studies were approved by the Review Board of the Medical College of Xiamen University.

Transfection procedures and optimum design in different cell lines. To acquire the optimal transfection efficiency in vitro, the cell confluence and the mass ratio of Sofast to DNA must be optimized. Various cell culture plates and dishes (96-well, 48-well, 24-well, 12-well and 6-well plates; 35-mm, 60-mm and 90-mm dishes) were used to culture cells at different initial cell numbers. Different mass ratios of Sofast to DNA were also arranged to investigate the transfection efficiency in vitro.

Optimum vaccination of adherent cells. In order to determine the optimum vaccination of adherent cells, cells were seeded into different cell culture plates and dishes according to the data in Table I.

Preparation of Sofast/DNA complex (with representative 24-well plates). First, $0.6 \mu \mathrm{g}$ plasmid DNA was diluted in $30 \mu \mathrm{l}$ of culture medium (DMEM, opti-MEM, PBS buffer solution or $150 \mathrm{mM} \mathrm{NaCl}$ solution) without serum and antibiotics, and the solution was gently mixed. Second, 1-1.8 $\mu 1$ Sofast was diluted in $30 \mu \mathrm{l}$ of culture medium without serum or antibiotics, and was gently and thoroughly mixed. Subsequently, $30 \mu \mathrm{l}$ Sofast was added dropwise into the DNA solution, while the solution was mixed well. It should be noted that the sequence in which these two solutions are mixed may affect the transfection efficiency: mixing in reverse would lead to a more than 10 -fold decline in transfection efficiency (6). Finally, the mixture was incubated at room temperature for 15-20 $\mathrm{min}$.

Transfection. Sofast/DNA complex $(60 \mu \mathrm{l})$ was added to each well and mixed gently. After the cells were incubated at $37^{\circ} \mathrm{C}$ with $5 \% \mathrm{CO}_{2}$ for $24-48 \mathrm{~h}$, the expression of the reporter gene was analyzed and the transfection efficiency was measured.

Transfection procedure for suspended cell lines. The procedure for transfecting suspended cells was similar to that used for adherent cells, with the following exception: after culturing for $1 \mathrm{~h}$, the suspended cells were mixed with Sofast/ DNA complex, which was dropped into the culture dishes in the same manner as for the adherent cells. The cells were then maintained for another $24-48 \mathrm{~h}$, and the transfection efficiency was evaluated.

Determination of optimal time after transfection for analysis. HeLa cells were transfected with pEGFPN1 plasmid according to the common transfection protocol (2). Alterations in GFP expression were observed in the pEFGPN1-transfected cells at various time points $(6,12,18,24,32,40,48,64$ or 72 h).

Facilitation of transfection efficiency by diINF-7. The facilitation of Sofast-mediated gene transfection by diINF-7, a fusogenic peptide, was investigated. diINF-7 with 24 amino acids was synthesized by the standard chemical, N-(9fluorenyl) methoxycarbonyl (synthesized by the Academy of Military Medical Sciences, China). diINF-7 at a final concentration of $0.5 \mu \mathrm{g} / \mathrm{ml}$ was then dissolved into the Sofast working solution $(4.0 \mathrm{ml}$ saline, $5.9 \mathrm{ml}$ DMSO and $0.1 \mathrm{ml}$ glycerol). After being filtered with a $0.2 \mu \mathrm{m}$ filter, the mixture was allocated aseptically and stored at $4^{\circ} \mathrm{C}$.

Effect of diINF-7 on GFP expression in HeLa cells transfected with Sofast. HeLa cells were seeded in 24-well plates at an initial cell number of $2.0 \times 10^{5}$ cells/well. The bulk volume of the culture medium was $500 \mu \mathrm{l}$ per well. The cells were incubated for $16-24 \mathrm{~h}$ at $37^{\circ} \mathrm{C}$ in humidified air with $5 \% \mathrm{CO}_{2}$ until reaching 40-50\% confluency. pEGFPN1 plasmid $(0.6 \mu \mathrm{g})$ was dropwise diluted in $30 \mu \mathrm{l}$ serum and antibiotic-free DMEM, and then was gently mixed well; $1.8 \mu$ l Sofast and 0.9 $\mu \mathrm{l}$ diINF-7 were both diluted in $30 \mu \mathrm{l}$ DMEM, and then the $30 \mu$ l Sofast-diINF-7 mixtures were dropwise added into the $30 \mu \mathrm{l}$ pEGFPN1 plasmid solution. After incubation at room temperature for $15 \mathrm{~min}$, the Sofast-diINF-7/DNA complex was formed. The Sofast-diINF-7/DNA complex $(60 \mu \mathrm{l})$ was added to each well and the cells were maintained for $24 \mathrm{~h}$ at $37^{\circ} \mathrm{C}$ with $5 \% \mathrm{CO}_{2}$. Gene expression analysis revealed 
Table II. Proper proportion of Sofast and DNA in different cell culture devices.

\begin{tabular}{lccccc}
\hline Cell culture devices & $\begin{array}{c}\text { DNA } \\
(\mathrm{mg})\end{array}$ & $\begin{array}{c}\text { DNA solution } \\
\text { volume }(\mathrm{ml})\end{array}$ & $\begin{array}{c}\text { Sofast volume } \\
(\mu \mathrm{l})\end{array}$ & $\begin{array}{c}\text { Sofast solution } \\
\text { volume }(\mathrm{ml})\end{array}$ & $\begin{array}{c}\text { Sofast/DNA complex } \\
\text { volume }(\mu \mathrm{l})\end{array}$ \\
\hline 96-well plates & 0.15 & 7.5 & $0.2-0.5$ & 7.5 & 15 \\
48-well plates & 0.3 & 15 & $0.5-0.9$ & 15 & 30 \\
24-well plates & 0.6 & 30 & $1.0-1.8$ & 30 & 60 \\
12-well plates & 1.0 & 50 & $1.0-3.0$ & 50 & 100 \\
6-well plates & 2.0 & 100 & $3.0-6.0$ & 100 & 200 \\
35-mm Petri dishes & 2.0 & 100 & $3.0-6.0$ & 100 & 200 \\
60-mm Petri dishes & 6.0 & 300 & $9.0-18.0$ & 300 & 600 \\
100-mm Petri dishes & 16.0 & 800 & $24.0-48.0$ & 800 & 1600 \\
\hline
\end{tabular}

that the GFP-positive cells shed bright green fluorescence, while the GFP-negative cells were non-fluorescent. In each view, 100 cells were selected to calculate the percentage of GFP-positive cells, and the procedures were repeated in three representative views. Sofast without diINF-7 served as a control.

Effect of diINF-7 dosage on the transfection efficiency of Sofast. In order to determine the effect of diINF-7 dosage on transfection efficiency, pGL3 plasmid was transfected into HeLa cells using Sofast with different concentration of diINF-7, then luciferase activity was detected. A series of diINF-7 dosages (3.84 $\mu \mathrm{l}, 1.92 \mu \mathrm{l}, 0.96 \mu \mathrm{l}, 0.48 \mu \mathrm{l}, 0.24 \mu \mathrm{l}$, $0 \mu \mathrm{l}$ ) was applied to $0.6 \mathrm{mg}$ pGL3 plasmid and $1.92 \mathrm{ml}$ Sofast. Luciferase activity in the transfected Hela cells was evaluated according to the instructions manual, and the final result was presented as RLU/mg protein.

Effect of Sofast dosage on transfection efficiency in the presence of diINF-7. In order to evaluate the effect of Sofast dosage on transfection efficiency in the presence of diINF-7, a gradient mass ratio of Sofast to DNA (16:1, 8:1, 4:1, 2:1, $1: 1)$ was created by changing the amount of Sofast $(1.92 \mu 1$, $0.96 \mu \mathrm{l}, 0.48 \mu \mathrm{l}, 0.24 \mu \mathrm{l}, 0.12 \mu \mathrm{l})$, while keeping the amount of diINF-7 to half that of the Sofast and always using $0.6 \mathrm{mg}$ pGL3 plasmid. Luciferase activity in the transfected Hela cells was evaluated according to the instructions manual, and the final result was presented as RLU/mg protein (2).

Effect of salt concentration in working solution on transfection efficiency in vivo and in vitro. Sofast cationic polymer (50 $\mathrm{mg}$ ) was dissolved in $10 \mathrm{ml}$ working solution A $(150 \mathrm{mM}$ $\mathrm{NaCl}, 1 \%$ glycerol), solution B (5\% glucose, $1 \%$ glycerol) and solution C (75 mM NaCl, 50\% DMSO, $1 \%$ glycerol) for a final concentration of $5 \mathrm{mg} / \mathrm{ml}$. After heating at $56^{\circ} \mathrm{C}$ and filtering with a $0.2 \mu \mathrm{m}$ membrane filter, the working solutions $\mathrm{A}, \mathrm{B}$ and $\mathrm{C}$ for the gene vector were prepared.

In vitro test. For the in vitro test, the pGL3 plasmid was transfected into both HEK293 cells and HeLa cells using Sofast A, B and C. The detailed transfection protocol was as previously described (2). Briefly, $20 \mu \mathrm{g}$ pGL3 plasmid was diluted in $1 \mathrm{ml}$ Opti-MEM, and then $64 \mu \mathrm{l}$ Sofast $(5 \mathrm{mg} / \mathrm{ml})$ was dropped into this pGL3 plasmid diluent. The Sofast to DNA mass ratio was 16:1. After vortex oscillation and incuba- tion for $15 \mathrm{~min}$ at room temperature, $60 \mu \mathrm{l}$ Sofast/DNA complex was dropped into the cell culture medium and was mixed well. The cells were then maintained for $48 \mathrm{~h}$ at $37^{\circ} \mathrm{C}$ with $5 \% \quad \mathrm{CO}_{2}$. The culture medium was decanted. After washing once with PBS, cells were lysed with lysis buffer, agitated at room temperature for $10 \mathrm{~min}$, and finally collected in $1.5 \mathrm{ml}$ centrifuge tubes. The suspension was centrifuged for $20 \mathrm{~min}$ at $4^{\circ} \mathrm{C}$ at $5000 \mathrm{rpm} / \mathrm{sec}$. After adding $10 \mu \mathrm{l}$ fluorescer, a portion of the supernatant was used to measure the luciferase activity. Another $6 \mu \mathrm{l}$ of the supernatant was used to determine the protein concentration. The final result was presented as RLU/ mg protein.

In vivo test. For the in vivo test, Sofast with working solution $\mathrm{A}, \mathrm{B}$ and $\mathrm{C}$ was used to transfect the pEGFPN1 plasmid into mice, and then GFP expression in the lung, liver and kidney cells was investigated. The detailed transfection protocol was as previously described (2). Four groups were formed at randomly from 10 male guinea pigs with a body weight of 250-300 g: Group A, Sofast A, 3 male guinea pigs; Group B: Sofast B, 3 male guinea pigs; Group C: Sofast C, 3 male guinea pigs; and group $\mathrm{D}$ : negative control, 1 male guinea pig. Tail intravenous injections were performed as follows: $50 \mu \mathrm{g}$ pEGFPN1 plasmid and $75 \mu \mathrm{l}$ Sofast A, B, C were diluted in $2 \mathrm{ml} \mathrm{5 \%}$ glucose solution. Next, $2 \mathrm{ml}$ Sofast working solution $\mathrm{A}, \mathrm{B}$ and $\mathrm{C}$ was respectively dropped into the pEGFPN1 plasmid diluents mentioned above and incubated at room temperature for $15 \mathrm{~min}$. The guinea pigs in groups A, B and $\mathrm{C}$ were injected with $200 \mu \mathrm{l}$ Sofast/pEGFPN1 complex, while group D was injected with $200 \mu 1$ pEGFPN1 plasmid diluents. After transfection for $48 \mathrm{~h}$, the guinea pigs were sacrificed and the lung and kidney were examined under a fluorescence microscope.

\section{Results}

Optimal transfection procedures in the different cell lines. The data obtained indicate that Sofast was capable of successfully transfecting exogenous genes into many primary cell lines or transformed cell lines, adherent cells and suspended cells, and was suitable for transient transfection and stable transfection. To date, Sofast has been successfully used to transfect 42 cell lines derived from humans, monkeys and dogs.

The results indicate that Sofast possesses optimum transfection efficiency when the cells are 50-80\% confluent, which 

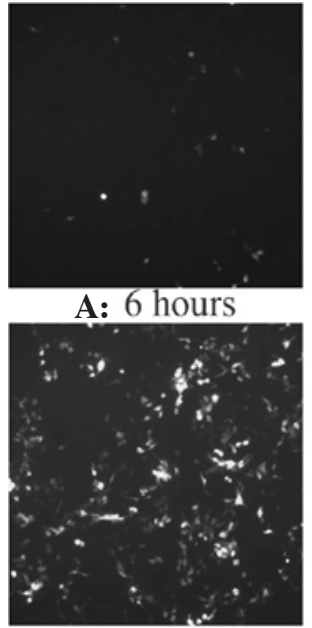

E: 36 hours

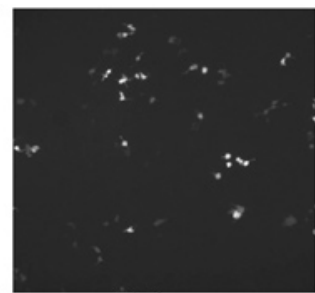

B: 12 hours

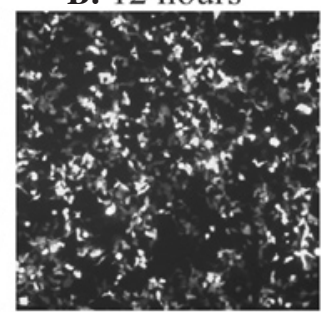

F: 48 hours

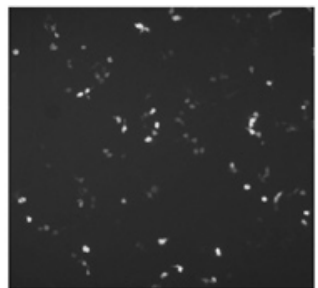

C: 18 hours

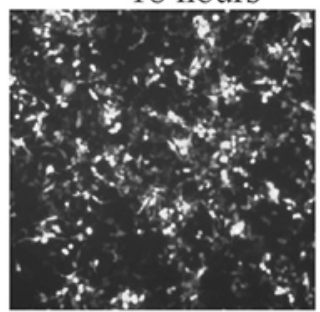

G: 60 hours

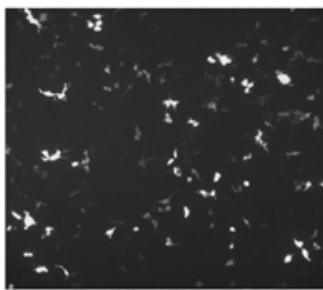

D: 24 hours

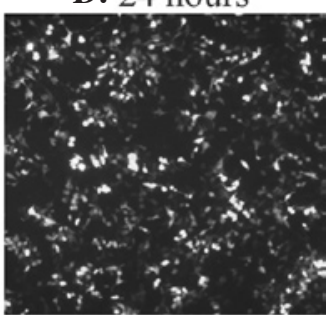

F: 72 hours

Figure 1. The level of GFP expression in Hela cells at different times after transfection (x100). (A)-(H) show GFP expression in HeLa cells at 6, 12, 18, 24, 32, $40,48,56,64$ and $72 \mathrm{~h}$, respectively, after transfection.

A
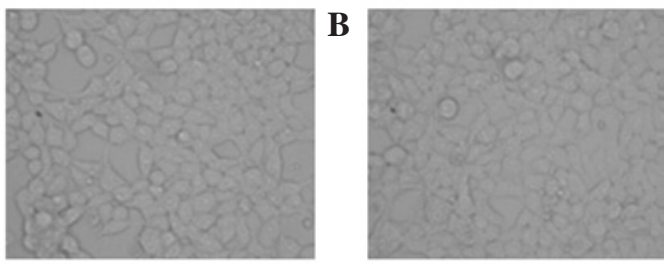

C

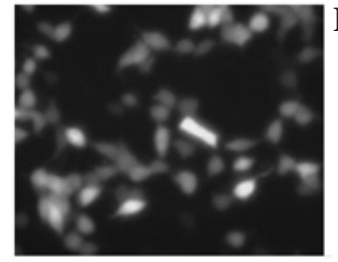

Transfected without diINF-7

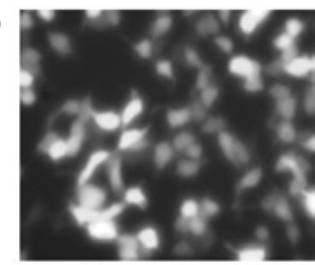

Transfected with diINF-7

Figure 2. GFP expression in HeLa cells transfected with and without diINF-7 (x400). Twenty-four hours after transfection the HeLa cell density in the groups with or without diINF-7 was identical: (A) HeLa cell density in the test group with diINF-7; (B) HeLa cell density in the control group without diINF-7; (C) GFP expression in Hela cells without diINF-7; (D) GFP expression in Hela cells with diINF-7.

varies slightly depending on the cell line. For transfecting the most commonly used cell lines, a cell confluence of $60-70 \%$ was optimal. Taking 24-well plates as an example, the ideal condition was to seed cells at the initial number of $8 \times 10^{4}$ $2.0 \times 10^{5}$ cells/well and to culture them for $18-24 \mathrm{~h}$ before transfection. In most cases, conducting transfection after the cells were attached to the substrate for several hours would result in the same efficiency. Cells that were insensitive to cytotoxicity were transfected immediately after inoculation. In order to obtain the optimum transfection efficiency in the suspended cells, we recommended that the transfection be performed after the cells were seeded for $1 \mathrm{~h}$.

To obtain a better transfection efficiency, the amounts of Sofast and DNA should be determined according to the area of the cell culture device used. Table II lists the suitable mass ratio of Sofast to DNA for performing experiments in different culture devices.

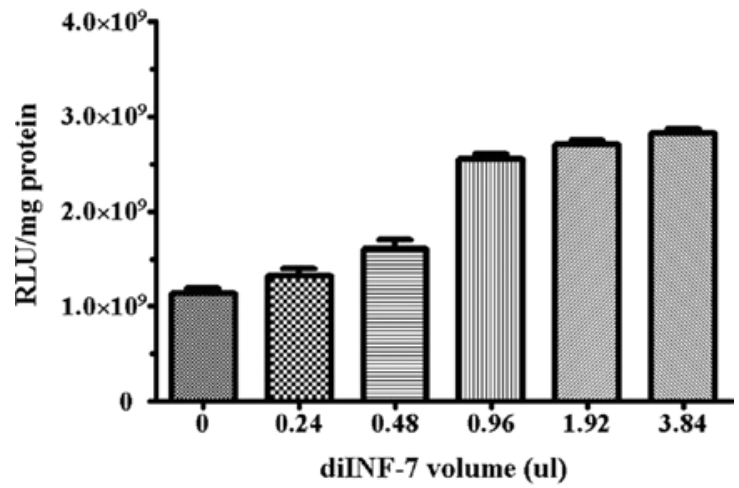

Figure 3. Dosage effects of diINF-7 on luciferase activity in HeLa cells X-axis: volume of diINF-7 $(0.5 \mu \mathrm{g} / \mathrm{ml})$. With increasing dosage of diINF-7, the luciferase activity was improved, indicating that diINF-7 could improve the transfection efficiency in a dose-dependent manner.

Optimization of time after transfection. GFP expression in Hela cells at different time points after transfection of pEGFPN1 plasmid using Sofast is shown in Fig. 1. The level of GFP expression gradually increased and reached a maximum at $48 \mathrm{~h}$. Subsequently, the level of GFP expression remained fairly constant, although the cells still underwent division, indicating that $48 \mathrm{~h}$ was the optimum time to acquire results after transfection.

Effect of diINF-7 on GFP expression in HeLa cells transfected with Sofast. The results indicate that, at $24 \mathrm{~h}$ after transfection, the cell density in the group with diINF-7 was identical to that in the control group without diINF-7, while the number of GFP-positive cells in the former group was markedly higher than that in the latter group. The positive rates were $55 \%$ and $35 \%$, respectively, which resulted in a 2 -fold difference in fluorescence intensity. (Fig. 2).

Effects of diINF-7 dosage on luciferase activity in HeLa cells. The results revealed that adding diINF-7 to the working solution improved transfection efficiency, which rose in 


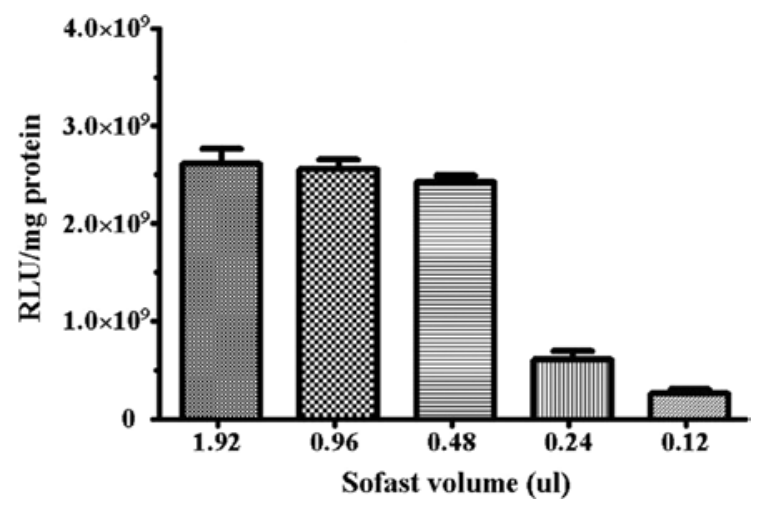

Figure 4. Dosage effects of Sofast on transfection efficiency. The results demonstrate that the transfection effiency kept steady when the volume of Sofast was a quarter of the initial volume under conditions of keeping the volume raito of diINF-7 to Sofast at $1 / 2$, indicating that diINF-7 improved the transfection efficiency.

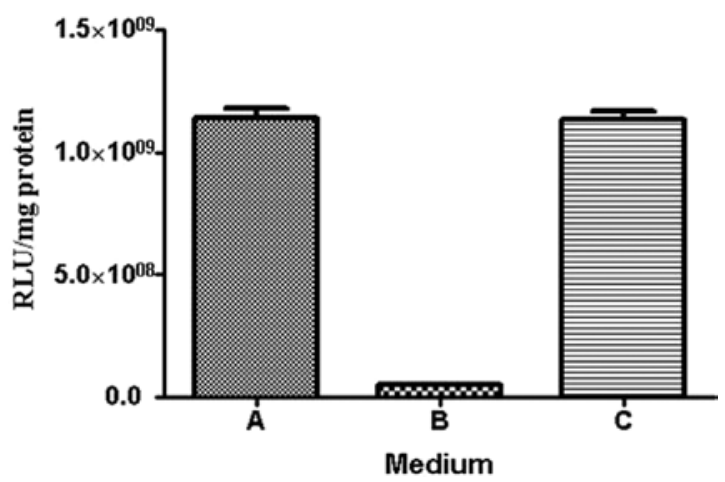

Figure 5. Luciferase activity in pGL3-transfected HEK293 cells using different working solutions containing various salt concentrations. (A) Sofast A, (B) Sofast B, (C) Sofast C. conjunction with the increase in the dosage of diINF-7. When the volume ratio of diINF-7 to Sofast was 1:2, the transfection efficiency was 2.5-fold higher than without diINF-7, indicating that it was significantly improved. Subsequently, the transfection efficiency was slightly, but not statistically significantly, increased in conjunction with an increase in diINF-7 (Fig. 3).

Effects of Sofast dosage on luciferase activity in HeLa cells in the presence of diINF-7. When the volume ratio of diINF-7 to Sofast was maintained at $1 / 2$, the transfection efficiency did not change when the volume of Sofast was decreased from 1.92 to $0.48 \mu \mathrm{l}$. During this procedure, the amount of Sofast was only a quarter of the initial amount and the mass ratio of Sofast to DNA ranged from 16:1 to 4:1; however, when the volume of Sofast was $1 / 8$ or $1 / 16$ of the initial volume, the transfection efficiency underwent a 4.2 and a 22.1-fold decline, respectively. (Fig. 4).

Effect of salt concentration in working solution on transfection efficiency in vivo and in vitro.

In vitro test. pGL3 plasmid was transfected into HEK293 cells using Sofast at different working solution. The luciferase activity in HEK293 cells is shown in Fig. 5. In vitro, when the working solution was salt-free, the transfection efficiency was markedly lower than in the working solutions containing $150 \mathrm{mM} \mathrm{NaCl}$ or $75 \mathrm{mM} \mathrm{NaCl}$, which had a 107-fold decline; however, there was no significant difference in transfection efficiency between $150 \mathrm{mM} \mathrm{NaCl}$ and $75 \mathrm{mM} \mathrm{NaCl}$. Similar results were also obtained from experiments performed with HeLa cells, and the transfection efficiency underwent an almost 100-fold decline compared with the working solutions containing salts.

In vivo test. At $48 \mathrm{~h}$ after tail intravenous injection with Sofast A, B, C and pEGFPN1 plasmid solution, the guinea
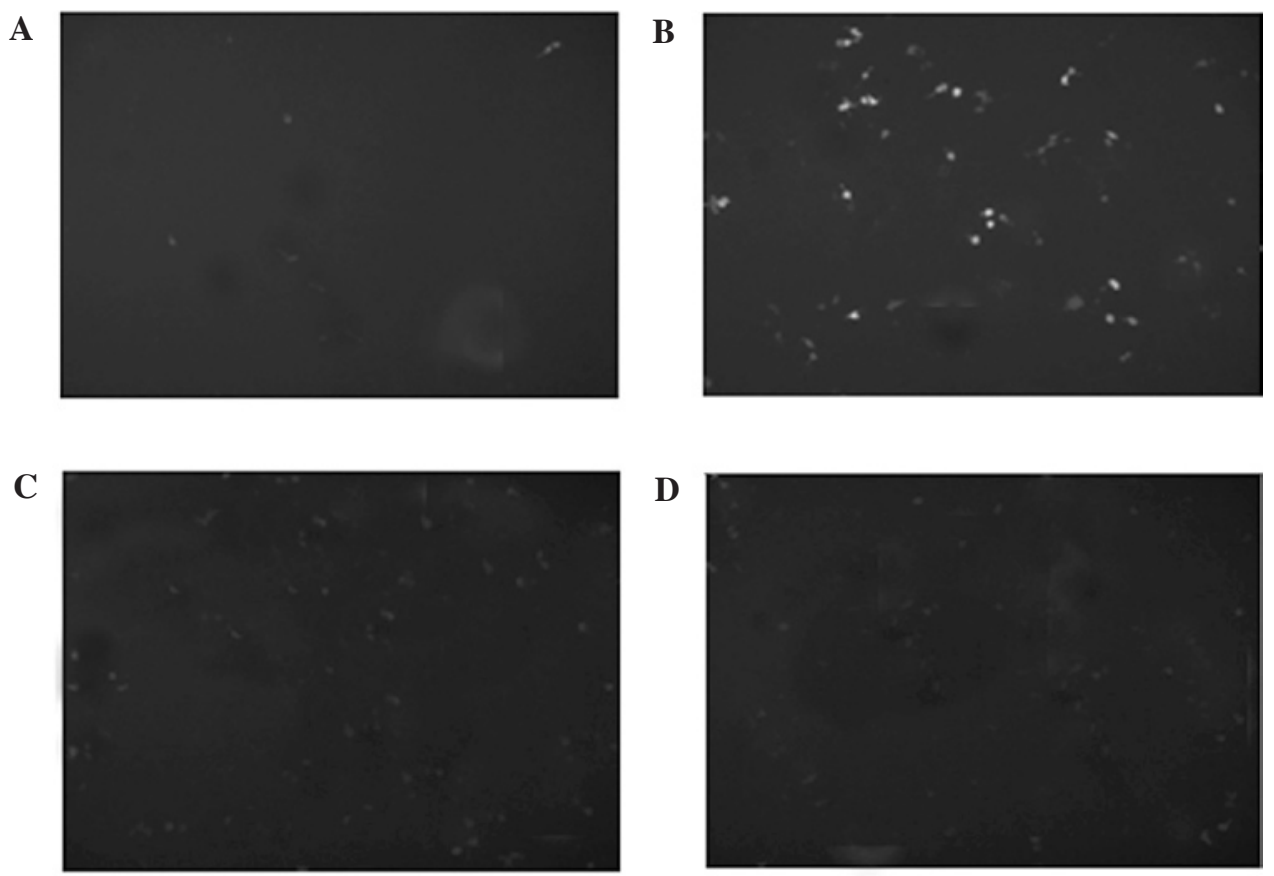

D

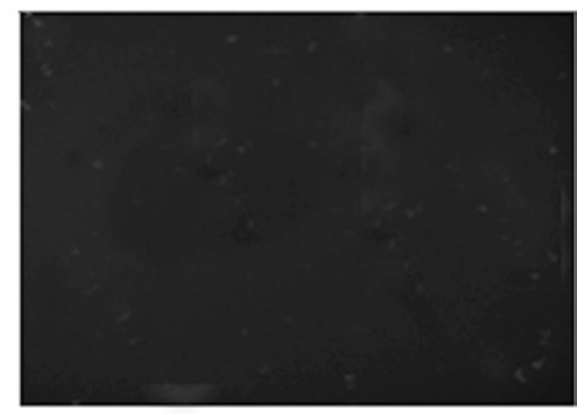

Figure 6. GFP expression in guinea pig kidney tissues $48 \mathrm{~h}$ after injection with different gene vector/pEGFPNI complexes (x100). The results prove that gene vector with salt $(150 \mathrm{mM}$ or $75 \mathrm{mM} \mathrm{NaCl})$ had no tranfection efficiency, while gene vector with $5 \%$ glucose could be just suitable for in vivo transfection. (A) Sofast A, (B) Sofast B, (C) Sofast C, (D) control. 
pigs were sacrificed. Lung, liver, and kidney were immersed in frozen embedding medium, and the frozen sections were observed under a fluorescence microscope. Green fluorescence was observed in the tissues of the liver, lungs and kidney in Group B, while there was no signal detected in Groups A and $\mathrm{C}$ or in the control group, D. Fig. 6 shows GFP expression in guinea pig kidneys $48 \mathrm{~h}$ after intravenous injection with different gene vectors.

\section{Discussion}

The results of the present study indicate that the efficiency of gene delivery mediated by the gene vector was affected by many factors, including the features and activities of the cell line, cell culture conditions, quality of DNA or RNA and transfection protocols (7). To achieve a better transfection efficiency in vitro, it was necessary to optimize the conditions of the transfection using Sofast, including the initial cell numbers and the mass ratio of Sofast to DNA. We optimized the cell confluence and the mass ratio of Sofast to DNA in different culture dishes or plates (96-well, 48-well, 24-well, 12-well and 6-well plates; 35-mm, 60- $\mathrm{mm}$ and 90-mm Petri dishes) and identified the optimal conditions for Sofast. Although we have demonstrated that Sofast had very low toxicity in most cell lines, there remain many cell lines that are sensitive to Sofast. We suggest using fresh culture medium to replace the Sofast/DNA complex 2-4 h after transfection, which aids in improving transfection efficiency and lowering cytotoxicity.

Cell types affected the efficiency of gene vector-mediated gene transfection (8), but for reasons which were unclear. Our current results indicate that Sofast was successfully transferred into more than 40 types of cell lines derived from humans, mice and monkeys. We found that the shorter the cell doubling time and the faster the cell divided, the higher the transfection efficiency, such as in tumor cells. In vivo, transfection experiments showed that endothelial cells, macrophages and monocytes were the most easily transfected cell types. This may be due to the strong phagocytic capacity and immune function of these cells in presenting antigens. In terms of the different tissues and organs, transfection efficiency in the lung was significantly higher than in other organs, such as the liver, spleen and kidney, which may be attributable to the easy sedimentation of the complexes when they pass through the lung capillaries. By analyzing GFP expression in different organs of mice after intravenously injecting them with Sofast/ pEGFPN1 complex, we also confirmed a high transfection efficiency in the lung.

Cell density to some extent influenced transfection efficiency (9). For example, cationic liposomes often require a higher cell density or a much higher number of suspended cells for micro-cell toxicity, such as $90 \%$ of cell confluence (10), while for some polyamine or non-liposomal transfection reagents, the cell confluence usually ranges from $40-80 \%$ (4). The general principle for acquiring a better transfection efficiency is to transfect cells under their optimum physiological state. For Sofast, good transfection efficiency was reached when the cell confluence ranged between 50-80\%, with slight variations depending on the cell line. For the most commonly used cell lines, we recommended a cell confluence of $60-70 \%$. In most cases, transfection was conducted within several hours of the cells attaching to substrates. In cells that are insensitive to cytotoxicity, transfection may be performed immediately after inoculation.

Antibiotics such as penicillin and streptomycin have often been used to protect cells from bacterial contamination. These antibiotics are generally non-toxic to eukaryotic cells. However, some gene vectors improve cell permeability, which allows the antibiotics to enter the cells, indirectly leads to cell death, and finally lowers the transfection efficiency (11). We recommend the use of serum and antibiotics-free DMEM to dilute DNA and the gene vector Sofast, in order to reduce possible contamination through rigorous operations.

The N/P value, the mole ratio of amino groups of cationic polymers to the phosphate groups of DNA (to facilitate the conversion, gene vector/DNA mass ratio was generally used), was the key to transfection efficiency (12). Within a certain range, transfection efficiency increased along with enhancement of the N/P ratio, and then reached a fair value, while the toxicity also kept increasing. Our study found that in the in vitro transfection experiments, the recommended mass ratio of Sofast to DNA was 16:1; while in vivo, the mass ratio ranged between 5:1-8:1. Generally, transfection benefited from higher N/P values, but a high N/P value might lead to high cytotoxicity. Therefore, for transfection in different cell lines, the best $\mathrm{N} / \mathrm{P}$ value should be determined according to the recommended value.

In terms of the analyzing time of transfection, there were two kinds of transfection: transient transfection and stable transfection. By transient transfection, the exogenous nucleonic acid was not capable of integrating with the genome and preserving the short-term high expression level of target gene for 24-96 h. In the present study, we transfected pEGFPN1 plasmid into HeLa cells using Sofast, and found that GFP expression kept increasing and reached a peak value at 48 h. At later time points, the GFP expression changed only slightly, although cells still underwent division, suggesting that $48 \mathrm{~h}$ after transfection was the optimum time to analyze the results.

We further examined the diINF-7-induced promotion of Sofast transfection efficiency. Gene vectors transport exogenous nucleic acid molecules into cells through three pathways (13): extracellular release, formation of endosomes by endocytosis, and direct penetration. Sofast/DNA complexes are positively charged and can be absorbed by the negatively charged cell membrane, then transport the DNA into cells through membrane fusion and endocytosis and occasionally by direct infiltration, after which the endosome is formed and DNA is released from the endosomes into the cytoplasm and finally into the nucleus to be transcribed and expressed. We postulated that a certain membrane fusion protein acts as a catalyzer during the endocytic process in order to overcome the energy barrier (14). It was confirmed that the gene fusion peptide Haemophilus influenzae hemagglutinin-derived peptides-7 (INF-7) had strong membrane fusion properties and could be used to promote the transfection efficiency of non-viral gene vectors (15-18). diINF-7 was a $\mathrm{pH}$-dependent fusion peptide with 24 amino acids, and as the dimer of INF-7, had an N-terminal structure similar to that of hemagglutinin HA-2 of the influenza virus. diINF-7 is capable of promoting gene transfection, and has been successfully used in cationic liposome types of gene vectors $(19,20)$. 
Transfection of pEGFPN1 plasmid into HeLa cells resulted in a significant increase in the number of GFP-positive cells and in the fluorescence intensity in the test group with diINF-7, indicating that diINF-7 significantly enhanced the transfection efficiency of Sofast. Luciferase activity in HeLa cells increased along with the enhancement of the amount of diINF-7. When the dosage of diINF-7 was up to $1 / 2$ of the dosage of Sofast, the transfection efficiency was significantly improved, and was 2.5-fold higher than that without diINF-7. Subsequently, the transfection efficiency was steady even when the amount of diINF-7 kept increasing. Interestingly, in the presence of diINF-7, the transfection efficiency underwent little change when the amount of Sofast was reduced to a quarter of the original amount; however, when the amount of Sofast was reduced to $1 / 8$ or $1 / 16$ of the original amount, the transfection efficiency was markedly decreased. Therefore, we recommend the reduction of the amount of Sofast to control costs in the presence of diINF-7.

The effect of salt concentration in the working solution on transfection efficiency was assessed both in vitro and in vivo. Salt concentration in the working solution of the gene vector is a key element for transfection efficiency. In a buffer solution containing salt, the charge of the cationic polymer gene vector/ DNA complexes is weakened, the electrostatic repulsive forces among microparticles are decreased, and the microparticles aggregate to form large particles (21). The complex is rapidly deposited and increases the intermolecular force with the cell surface, finally improving the transfection efficiency. In the present study, transfection efficiency was improved through enhancing the salt concentration and altering the complex size $(22,23)$. Interestingly, a salt-free cationic polymer gene vector/DNA complex with 5\% glucose was better for in vivo transfection due to the micro-ground particles, and the transfection efficiency was 100-fold higher than that in the salt medium (23). At present, there are many hypotheses regarding the effect of salt on transfection efficiency both in vitro and in vivo, and the detailed mechanisms have yet to be defined. Results from our study also confirm this point. Therefore, in the present study, a salt-free working solution was used for in vivo testing, while a working solution with salt was used for in vitro testing.

In conclusion, based on our previous study, the present research further explored and optimized the properties of Sofast and transfection conditions, such as the cell density, transfection time, N/P values and the time after transfection, as well as the effects of the fusion peptide diINF-7 on transfection efficiency. Finally, the study established optimal working conditions for transfecting commonly used cells using Sofast, and provided the basis for the in vitro and in vivo applications of Sofast.

\section{Acknowledgements}

This study was supported by the Natural Science Foundation of the Jiangsu Province (Grant No.: BK2007232), the Natural Science Foundation of the Fujian Province (Grant No.: 2009J01200), the Key projects in the Fujian Province Science and Technology Program (Grant No.: 2009D019), and the projects of the Xiamen Science and Technology Program (Grant No.: 3502Z20089015).

\section{References}

1. Park J, Na K, Woo D, et al: Non-viral gene delivery of DNA polyplexed with nanoparticles transfected into human mesenchymal stem cells. Biomaterials 31: 124-132, 2010.

2. Shi S-L, Dan B, Lin L-R, et al: Synthesis and characterization of a novel cationic polymer gene delivery vector. Int J Mol Med 26: 491-500, 2010.

3. Hill IR, Garnett MC, Bignotti F and Davis SS: Determination of protection from serum nuclease activity by DNA-polyelectrolyte complexes using an electrophoretic method. Anal Biochem 291: 62-68, 2001.

4. Jing GJ, Fua ZG, Dan B, Lin LR, Yang TC and Shi SL: Development and evaluation of a novel nano-scale vector for siRNA. J Cell Biochem July 21, 2010 (Epub ahead of print).

5. Pouton CW and Seymour LW: Key issues in non-viral gene delivery. Adv Drug Deliv Rev 46: 187-203, 2001.

6. Boussif O, Zanta MA and Behr JP: Optimized galenics improve in vitro gene transfer with cationic molecules up to 1000 -fold. Gene Ther 3: 1074-1080, 1996.

7. Thomas J, Rekha M and Sharma C: Dextran-glycidyltrimethylammonium chloride conjugate/DNA nanoplex: a potential non-viral and haemocompatible gene delivery system. Int $\mathrm{J}$ Pharm 389: 195-206, 2010.

8. Mthunzi P, Dholakia K and Gunn-Moore F: Phototransfection of mammalian cells using femtosecond laser pulses: optimization and applicability to stem cell differentiation. Journal of Biomedical Optics 15: 041507, 2010

9. Hong L, Zhang J, Min J, et al: A role for MHBst167/HBx in hepatitis B virus-induced renal tubular cell apoptosis. Nephrol Dial Transplant 25: 2125-2133, 2010.

10. Schirrmann $\mathrm{T}$ and Büssow K: Transient production of scFv-Fc fusion proteins in mammalian cells. In: Antibody Engineering Vol 2. 2nd edition. Kontermann $\mathrm{R}$ and Dübel $\mathrm{S}$ (eds). SpringerLink, New York: pp387-398, 2010.

11. Wu G, Wu H, Fan X, et al: Membrane aggregation and perturbation induced by antimicrobial peptide of S-thanatin. Biochem Biophys Res Commun 395: 31-35, 2010.

12. Peng S, Yang M, Su C, et al: Effects of incorporation of poly ([gamma]-glutamic acid) in chitosan/DNA complex nanoparticles on cellular uptake and transfection efficiency. Biomaterials 30: 1797-1808, 2009

13. Fretz MM, Mastrobattista E, Koning GA, Jiskoot W and Storm G: Strategies for cytosolic delivery of liposomal macromolecules. Int J Pharm 298: 305-309, 2005.

14. Wadia JS and Dowdy SF: Protein transduction technology. Curr Opin Biotechnol 13: 52-56, 2002.

15. Wolfert MA and Seymour LW: Chloroquine and amphipathic peptide helices show synergistic transfection in vitro. Gene Ther 5: 409-414, 1998.

16. Wagner E: Application of membrane-active peptides for nonviral gene delivery. Adv Drug Deliv Rev 38: 279-289, 1999.

17. Subbarao NK, Parente RA, Szoka FC, Jr., Nadasdi L and Pongracz K: pH-dependent bilayer destabilization by an amphipathic peptide. Biochemistry 26: 2964-2972, 1987.

18. Plank C, Oberhauser B, Mechtler K, Koch C and Wagner E: The influence of endosome-disruptive peptides on gene transfer using synthetic virus-like gene transfer systems. J Biol Chem 269: 12918-12924, 1994.

19. Godbey WT, Wu KK and Mikos AG: Poly(ethylenimine) and its role in gene delivery. J Control Release 60: 149-160, 1999.

20. Mastrobattista E, Koning GA, van Bloois L, Filipe AC, Jiskoot W and Storm G: Functional characterization of an endosome-disruptive peptide and its application in cytosolic delivery of immunoliposome-entrapped proteins. J Biol Chem 277: 27135-27143, 2002

21. Wightman L, Kircheis R, Rossler V, et al: Different behavior of branched and linear polyethylenimine for gene delivery in vitro and in vivo. J Gene Med 3: 362-372, 2001.

22. Ogris M, Steinlein P, Kursa M, Mechtler K, Kircheis R and Wagner E: The size of DNA/transferrin-PEI complexes is an important factor for gene expression in cultured cells. Gene Ther 5: 1425-1433, 1998.

23. Blessing T, Kursa M, Holzhauser R, Kircheis R and Wagner E: Different strategies for formation of pegylated EGF-conjugated PEI/DNA complexes for targeted gene delivery. Bioconjug Chem 12: 529-537, 2001. 